\title{
SINOBAS, RESULTADOS DE CINCO AÑOS DE CIENCIA CIUDADANA
}

\author{
Delia Gutiérrez Rubio $^{(1)}$, Jesús Riesco Martín ${ }^{(1)}$, Salvador Ponce Gutiérrez ${ }^{(1)}$ \\ (1) Agencia Estatal de Meteorología (AEMET)
}

Tras cinco años de uso operativo, SINOBAS, el Sistema de Notificación de Observaciones Atmosféricas Singulares de AEMET, destaca como un componente fundamental de la estrategia de AEMET de crowdsourcing e Internet de las Cosas (IoT).

Mediante esta aplicación web, AEMET recoge información de cualquier ciudadano sobre la ocurrencia de fenómenos meteorológicos que, por su escala, pueden pasar desapercibidos para las redes de observación convencional y para los sistemas de teledetección, pero que tienen relevancia y pueden causar un impacto significativo en la población, como por ejemplo tornados, granizadas singulares, precipitaciones súbitas torrenciales, nevadas singulares, etc.

El sistema está operativo desde abril de 2013, no obstante, dado que permite informar no solo de eventos recientes, sino también de episodios históricos de interés, también es posible encontrar registros anteriores a dicha fecha y, de hecho, se está convirtiendo en una valiosa base de datos de fenómenos meteorológicos que, de otro modo, serían difícilmente localizables.

Actualmente SINOBAS cuenta con más de un millar de usuarios registrados y cerca de mil fenómenos meteorológicos "singulares" reportados desde su puesta en operación. Todos los reportes introducidos en el sistema son después validados por técnicos de AEMET y se les asigna una fiabilidad.

SINOBAS también gestiona una cuenta de Twitter, @AEMET_SINOBAS, que es un canal ágil de comunicación con el público y una vía de popularización del sistema y seguimiento de la actualidad meteorológica.

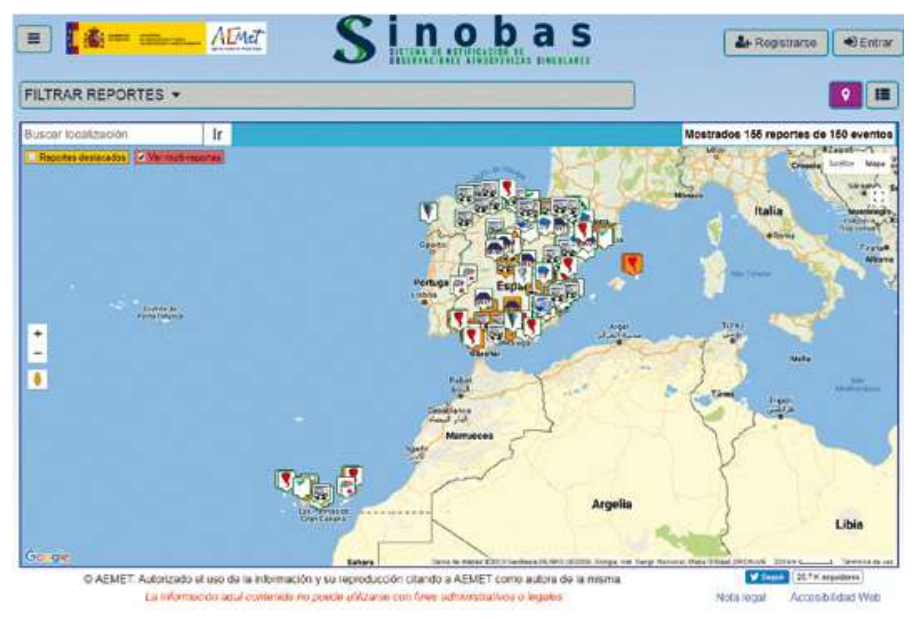

Fig. 1.- Aspecto de la nueva aplicación web del sistema SINOBAS 
La aplicación web, desarrollada en AEMET, está basada en software libre y referenciada geográficamente sobre Google Maps. Tras cinco años de uso operativo, se ha llevado a cabo una renovación integral, para adaptar el sistema a los avances tecnológicos. El nuevo web, lanzado el 31 de diciembre, incorpora las siguientes mejoras en su funcionalidad:

- El sistema permite aportar no sólo fotos y documentos pdf, sino también vídeos.

- El nuevo visor de detalles, visualiza fotos, vídeos y pdfs sin necesidad de salir de la web. Además rescata y visualiza los pdf's y vídeos (youtube o vimeo) recibidos como enlaces.

- El diseño está adaptado a cualquier tamaño de pantalla y dispositivo.

- El formulario de filtro puede realizar búsquedas de texto dentro de cualquier campo de los reportes y es más intuitivo. Además no recorta la pantalla de visualización.

- El formulario de nuevos reportes es más intuitivo y se accede en un solo paso.

- El diseño web es más moderno y y también se ha modernizado el logo.

- Dispone de nuevas posibilidades de interacción de los usuarios con el sistema a través de "compartir", "me gusta" y "favoritos".

- Se ha optimizado el código fuente y actualizado a nuevas versiones de PHP, MySQL, JQuery y API's.

- Los tuits automáticos y correos electrónicos automáticos son más personalizables.

- La Web se aloja en un nuevo servidor más potente y moderno.

- La comunicación está cifrada mediante certificado SSL

Tras estos cinco años de experiencia, podemos resumir las siguientes lecciones aprendidas y retos en perspectiva:

\section{Lecciones aprendidas}

- SINOBAS se ha convertido en un componente principal de la implementación de la estrategia de AEMET en Crowdsourcing \& IoT.

- Twitter ha demostrado ser muy efectivo para la popularización del sistema.

- Las actividades de comunicación dentro y fuera de AEMET son un esfuerzo necesario y recompensado.

- Un equipo de administración y gestión pequeño (tres personas a tiempo parcial) puede suponer cierta vulnerabilidad.

\section{Planes y desafíos}

- Intercambio de datos con la ESWD.

- Encuentros regulares con aficionados. Campañas especiales sobre temas específicos (convección, estudios de campo,...).

- Formación de spotters.

- Desarrollo de una App para recogida de datos de ciudadanos. 